\title{
BURRICE ACADÊMICO-LITERÁRIA BRASILEIRA
}

\section{BRAZILIAN ACADEMIC AND LITERARY STUPIDITY}

\author{
Fabio Akcelrud Durão ${ }^{1}$
}

RESUMO: Este texto investiga a burrice acadêmica brasileira tendo como foco privilegiado o modo como se manifesta nos estudos literários. No que toca ao método, sugere que o objeto de análise devem ser os processos que estruturalmente geram a estupidez, mais do que manifestações específicas, por mais enfáticos que possam ser casos individuais. São três os âmbitos discutidos: 1. a relação entre a universidade de pesquisa e o projeto nacional-desenvolvimentista brasileiro; 2. a equivocada representação social da Área de Letras; e 3. as consequências decorrentes de uma concepção cientificista de tratamento da literatura.

PALAVRAS-CHAVE: Burrice. Universidade. Literatura.

ABSTRACT: This text scrutinizes Brazilian academic stupidity, focusing especially on the field of Literary Studies. Methodologically, it suggests that the proper object of investigation should be the processes that generate stupidity, rather than on specific manifestations of it. As far as such processes are concerned, three are discussed, namely: 1. the origin of Brazilian research universities as developmentalist projects; 2 . a misleading social representation of the field of Letters; and 3. the consequences of a scientificist approach to dealing with literature.

KEYWORDS: Stupidity. University. Literature.

\footnotetext{
${ }^{1}$ Doutor em Literatura (2003) pela Duke University, EUA. Mestre em Teoria e História Literária (1997) pela Universidade Estadual de Campinas (UNICAMP). Graduado em Português-Inglês (1994) pela Universidade Federal do Rio de Janeiro (UFRJ). Professor livre docente do Departamento de Teoria Literária da Unicamp. Campinas, São Paulo, Brasil. E-mail: fadurao@yahoo.com
} 


\section{OBSERVAÇÕES DE MÉTODO}

A ideia de pensar a burrice acadêmica mais sistematicamente já me perseguia há algum tempo, desde quando anotava meus Fragmentos Reunidos (2015). Buscando uma bibliografia sobre o tema, percebi que minha curiosidade coadunava-se com um interesse recente, pois se é verdade que a estupidez é um personagem importante, ainda que secundário, na história da filosofia, as publicações voltadas especificamente para a imbecilidade parecem ser bastante recentes. Avital Ronell (2003) realiza uma pesquisa filosófica; David Graeber (2015) faz uma antropologia da burocracia como a grande prática estultificante da modernidade; Bernard Stiegler (2015) associa a burrice ao regime de choque tecnológico, intensificado ao máximo depois da revolução computacional. Quando se pensa que em francês bêtise vem bête, assim como em português é possível diferenciar "besta" ou "burro" como substantivo e adjetivo, abre-se uma porta para se refletir sobre a conexão entre o mundo animal e o da insuficiência da razão, como o fez Derrida (2008), por exemplo. Vem daí uma primeira conclusão, a de que a idiotice é produtiva demais: ela é menos um objeto ou campo do que uma lente, menos uma qualidade isolável do que um acompanhante, parasita ou vírus. Uma vez que surge como tópico, ameaça ser detectável em todos os lugares, incluindo na universidade, que deveria por 
definição ser o seu oposto, se não imune, ao menos resistente. É por isso que qualquer discurso que se debruce sobre a burrice terá dificuldade de limitar-lhe o escopo, e é por isso que vale a pena começar com algumas palavras de cautela.

Como é sabido, o conteúdo dos objetos interfere em sua forma de exposição. Um trabalho sobre o riso deve tomar um cuidado especial para não ser maçante, um sobre Sade, pudico, e assim por diante. Como tema, a burrice coloca ao menos três problemas metodológicos preliminares inescapáveis. Em primeiro lugar, há um desconforto enunciativo, pois ao conteúdo proposicional que descreve a idiotice corresponde uma força ilocucionária e, consequentemente, uma posição discursiva, de inteligência. Esta, como outros termos positivos ("escritor", "poeta"), entra em contradição consigo mesma quando autodeclarada. Não é você, mas outra pessoa, que pode dizer que você é inteligente, escritor, poeta etc.; a autoproclamação incorre em uma contradição performativa ${ }^{2}$. A segunda complicação metodológica refere-se à tendência natural de situar a burrice em um nível antropológico, aproximando-a, assim, do mundo moral, e possibilitando toda espécie de descargas afetivas. Embora não haja imbecilidade sem pessoas, não são elas que, a rigor, a criam, porque, é óbvio, a criação de algo requer alguma espécie de inteligência. A burrice é mais produtivamente abordada, não como resultado das ações da pessoa, mas como estrutura, um dispositivo subjetivador; nesse sentido, ela pode estar entranhada nas instituições, pois, como pelo menos já desde Althusser (1995) sabemos, estas transformam indivíduos em sujeitos. Ambas dificuldades metodológicas podem ser superadas quando se atenta para o caráter dinâmico da burrice. Sua constatação não faz de você ipso facto inteligente, porque ela se deu neste caso, não podendo ser necessariamente extrapolada para outros. A condição de possibilidade do estudo da estupidez é a sua visibilidade, o fato de poder ser enquadrada; no entanto, dado que 1. a estultice é transmissível ${ }^{3}$, e 2 . que é impossível focalizar tudo o tempo todo, não

\footnotetext{
${ }^{2}$ Talvez seja necessário matizar a frase. Uma autoproclamação forte escaparia do paradoxo performativo, pois no caso de muitos autores o ser-escritor surge de uma autoimposição ou autogeração que antecede ao reconhecimento crítico, que deveria balizar a autorepresentação do escritor, e que facilitaria a composição de uma grande obra. A história da literatura está cheia de casos nos quais a transição para o magnum opus não se dá gradualmente, mas por saltos.

${ }^{3}$ Existe, assim, uma transmissão mimética, inconsciente da burrice. Gostaria de tomar a liberdade de citar aqui um trecho dos meus Fragmentos Reunidos (2015, p. 100-101), que tangencia esse ponto: "Uma experiência de banca. Me lembro de uma defesa de mestrado, na qual fui o segundo a usar a palavra. Antes de mim, arguiu um professor de mais longe, e como gostava de falar, tive tempo de procurar entender o que ali se passava. Concluí, em primeiro lugar, que era imperioso teorizar a merda, antes de mais nada pela dificuldade de diferenciá-la em vista de sua variedade, multiplicidade e ubiquidade. Neste caso, fiquei feliz em conseguir organizar a verborragia do colega em um esquema de quatro níveis, algo reminiscente da hermenêutica medieval. O primeiro era o literal, do simples nonsense, das palavras frouxas, dos
} 
há garantia a priori de que você não esteja sendo afetado. $\mathrm{O}$ emburrecimento é um tema tristemente ausente do debate acadêmico, embora seja dos fenômenos mais marcantes da vida intelectual hoje. Quantos não são os colegas cuja principal obra foi o doutorado? Quantos audaciosos radicais aos trinta anos de idade não se tornam entediantes conservadores aos cinquenta? De fato, há razões suficientes para se postular que a realidade social contém um componente emburrecedor; a imagem adequada da vida intelectual não é a de uma caminhada ou passeio, mas de andar em contra a sua corrente: para se permanecer onde se está é preciso continuar estudando, para progredir, estudar muito. Seja como for, no que se refere à segunda dificuldade, o enfoque na produção da burrice previne a sua singularização, permitindo que a raiva quanto a ocorrências específicas, que sem dúvida merece ter o seu lugar, possa ser descarregada em ambientes mais adequados que o da Wissenschaft.

O terceiro problema é de outra ordem, e se relaciona ao tom que muito naturalmente o discurso sobre a burrice acadêmica adota. Pois é bastante difícil evitar o registro lamurioso e o gesto de queixa, como que a apelar a alguma instância superior que pudesse remediar esse estado de coisas; e como a burrice precisa estruturalmente de um outro que a chame pelo nome, há sempre a tentação de encontrá-lo no passado, como se antes tudo fosse melhor. Note-se, porém, uma passagem como esta:

conceitos gelatinosos, da falta de coerência entre as frases. Mas como é impossível deixar de fazer sentido o tempo todo, logo surgia uma segunda camada, que se referia ao simples erro, e que já era um avanço, dado que já possuía alguma determinação. Acontece que a moleza e o engano não existem como mônadas, mas interagem com o meio ambiente, que poluem. Por isso, fui obrigado a refazer, na hora, a minha arguição, para substituir o máximo que pudesse os termos já empregados pelo falante antes de mim: "indivíduo", em lugar de "sujeito", "interpretação" ao invés de "exegese" etc. E foi justamente quando me dei conta disso, que vi aparecer o último nível, em toda a sua feiura: tanto o candidato, quanto eu e o orientador - além, especialmente, dos outros presentes - estávamos obrigados a ouvir aquilo e era impossível que o arguidor não o percebesse. Havia, assim, inegavelmente, um gozo do falar que, dentro dos limites do ritual, não tinha limite; e com ele entrava em cena o convite para uma perniciosa mímesis negativa. Mesmo que não compreendesse nada, ou melhor, justamente por não poder compreender nada, o candidato podia aprender as delícias de se ocupar essa posição: de poder falar, e os outros terem que ouvir, de poder escrever, e os outros se verem forçados a ler, de se ver julgando os outros sem entender de maneira alguma o que está em questão; em suma: o exercício de um gozo da pura autoridade, e que tem como condição de existência a ausência de qualquer conteúdo. Isso se confirmou quando fiquei sabendo que o orientador do falante arguidor era, ele mesmo, exatamente assim. A distopia da merda não reside na falta de contornos, no erro ou na poluição conceitual, mas em sua transmissão." 
As intimated above, the ideal of efficiency by force of which a large-scale centralized organization commends itself in these premises is that pattern of shared management whereby a large business concern makes money. The underlying business-like presumption accordingly appears to be that learning is a merchantable commodity, to be produced on a piece-rate plan, rated, bought and sold by standard units, measured, counted and reduced to staple equivalence by impersonal, mechanical tests. In all its bearing the work is hereby reduced to a mechanistic, statistical consistency, with numerical standards and units; which conduces to perfunctory and mediocre work throughout, and acts to deter both students and teachers from a free pursuit of knowledge, as contrasted with the pursuit of academic credits. So far as this mechanistic system goes freely into effect it leads to a substitution of salesman-like proficiency - a balancing of bargains in staple credits - in the place of scientific capacity and addiction to study.

O trecho está ousadamente criticando o sistema de créditos, da mensuração do ensino em unidades estandardizadas, que é aproximado à produção de mercadorias; em oposição a ele, encontra-se o "free pursuit of knowledge", a autonomia para pensar, que é a pedra de toque de qualquer reflexão sobre o conceito enfático de universidade, e que aqui impõe-se ao tempo, ao invés de serlhe subordinado. Acontece que estas palavras vêm de The Higher Learning in America (2015, p. 190), de Thorstein Veblen, publicado em 1918, porém concebido dezesseis anos antes. A surpreendente permanência dessas ideias sedimenta um tipo de escrita, e à medida que seus conteúdos tornam-se forma, passa a ser possível falar de um gênero composicional próprio, o da ideia de universidade $^{4}$. Seu traço definidor seria o contraste, geralmente negativo, de determinada configuração acadêmica de uma época com aquilo que seria o ideal do crítico. Se há algo de sóbrio em perceber que o ruim não é prerrogativa do presente, também existe algo de paralisante em notar a continuidade mau, como se não houvesse saída. ${ }^{5}$ Por isso é mais produtivo pensar o gênero ideia de universidade como sendo sustentado, não por regras organizadoras de um discurso simplesmente, mas pela dissonância entre universidade e configurações sociais específicas. ${ }^{6}$ A dialética subjacente a isso é a de que a universidade tanto se adequa à sociedade quanto a rejeita; ou, inversamente, que a sociedade tanto

\footnotetext{
${ }^{4}$ Seria possível concebê-lo como a contraparte conceitual do campus novel na literatura, como exemplificado por David Lodge entre outros.

${ }^{5}$ Tomei essa ideia de Collini (2017, p. 61-88); Teichgraeber III (2015) também fala da crítica à universidade como um tipo particular de escrita.

${ }^{6}$ É por isso que as meditações de Derrida a respeito da universidade sem condição (2003) são tão desalentadoramente ambíguas, pois se de um lado propõem uma forte ideia de autonomia, ontologizam a sua impossibilidade, que na verdade é resultado de um processo histórico e social.
} 
necessita da universidade para sua reprodução, quanto não a tolera como espaço livre que a critica. - E sob esse prisma não haveria razão para não supor que o ponto no qual nos encontramos leva o processo de esgarçamento da ideia universidade a um limite, depois do qual ficaria tão desfigurada que não mais mereceria seu próprio nome. ${ }^{7}$

\section{SOBRE A ACADEMIA BRASILEIRA}

O ensino superior no Brasil pode ser dividido em dois grandes grupos. De um lado há as instituições privadas. Salvo no caso de umas poucas confessionais, como algumas das Pontifícias Universidades Católicas (PUCs), são empresas de transmissão de conhecimento. Não há estabilidade no emprego para os docentes, sua titulação é a mínima exigida pelo governo ${ }^{8}$, a pesquisa é uma ficção, a subordinação do saber ao lucro é clara e aberta. Trata-se de entidades cuja função preponderante é formar mão de obra qualificada para o mercado de trabalho. A rigor, não é possível falar de burrice aqui, porque não existe uma pretensão à inteligência. Não está no horizonte de professores e alunos fazer o conhecimento mover-se; o que está em jogo, ao invés, é garantir que estes últimos adquiram determinados conteúdos para o exercício de postos de trabalho específicos. Do outro lado estão as universidades públicas. Não apenas são totalmente gratuitas, como também oferecem facilidades para a permanência estudantil, com restaurantes a preços subsidiados (em média com refeições a um ou dois dólares), opções de moradia gratuita, serviço médico e hospitalar de graça, bolsas para alunos de baixa renda, para pesquisas em nível de graduação e pós, etc. Todos os docentes têm a possibilidade de dedicar-se à pesquisa e obtém a estabilidade facilmente, após um período probatório de três anos; seus salários são uniformes, variando somente de acordo com a hierarquia acadêmica; e quando têm dedicação exclusiva ganham para estudar. Salvo alguns desenvolvimentos recentes, todas as disciplinas são ministradas por professores pesquisadores; o percentual de doutorandos ativos em atividades didáticas ainda é muito inferior ao dos Estados Unidos, por exemplo. Sustentando a universidade pública e gratuita encontra-se o discurso da inseparabilidade do ensino, pesquisa e extensão, o que significa que

\footnotetext{
${ }^{7}$ Em Entrepreneurial Literary Theory (2017, p. 251-258), Suman Gupta descreve sete estágios de adaptação do mundo acadêmico ao mercado; no último, já não faz mais sentido falar de universidade e um outro termo é necessário.

${ }^{8}$ Lembro-me do caso de um aluno que ao defender o doutorado me disse do medo que tinha de ser descoberto, pois se seu superior na instituição de ensino superior em que trabalhava ficasse sabendo, seria demitido, pois a cota mínima de doutores exigida pelo Ministério da Educação já havia sido cumprida.
} 
aprendizado e investigação devem acontecer juntos, e que a universidade tem responsabilidade social pelo saber que produz. Embora haja três sistemas, o municipal, o estadual e o federal, o primeiro raramente desenvolve atividades de pesquisa. Ainda está por ser feito um mapeamento completo dos efeitos da universidade pública na sociedade brasileira, para além da formação profissional, já em si obviamente da mais extrema importância; tal estudo certamente mostraria que muito do que melhor aconteceu na cultura e nas artes brasileiras de algum modo envolveu a universidade. ${ }^{9}$

É interessante notar que a oposição entre o sistema universitário privado e o público corresponde bem adequadamente a dois horizontes políticos díspares. $\mathrm{O}$ primeiro é o neoliberal, que afirma o Brasil como nação periférica, neocolonial. $\mathrm{O}$ saber é gerado no exterior e é comprado e aplicado no país. A estrutura completamente mercantil do ensino garante não apenas que uma pequena parcela da população seja capaz de frequentar o ensino superior, mas também que se instaure um claro sistema hierárquico segundo o qual quanto mais barata for a mensalidade, pior será o ensino; com isso, assegura-se a manutenção das estruturas de classe pelas sucessivas gerações. Como dissemos acima, tais instituições de ensino estão aquém da burrice; seriam objeto de estudo se o tema fosse o mal, ou a dominação, exploração, alienação ou outro semelhante. Quanto ao sistema público, que contêm universidades dignas do nome, ele é fruto direto do projeto nacional-desenvolvimentista, estando assim intimamente ligado a uma concepção de país independente. Grosso modo, é possível distinguir duas vertentes aqui. A primeira é a do catch-up, do queimar etapas para se equiparar às nações desenvolvidas; a segunda, mais ligada à esquerda, é a da dependência, que tem como pressuposto fundamental a ideia de que o subdesenvolvimento não é simplesmente um déficit, algo que poderia ser superado com o progresso, mas que ele é reproduzido a partir de relações internacionais desiguais. Como diz Celso Furtado, o "subdesenvolvimento é, portanto, um processo histórico autônomo, e não uma etapa pela qual tenham, necessariamente, passado as economias que já alcançaram grau superior de desenvolvimento" (2009, p. 161). Nesse contexto, o desenvolvimento tecnológico possui papel fundamental. De novo Furtado:

\footnotetext{
${ }^{9}$ Em um horizonte mais amplo, esse argumento transforma-se em topos conhecido na crítica cultural brasileira, a saber, o de que um aspecto central para a produção da cultura do país foi a porosidade entre a esfera erudita, letrada, e a popular.
} 
Numa simplificação teórica se pode admitir como plenamente desenvolvidas num momento dado, aquelas regiões em que, não havendo desocupação de fatores, só é possível aumentar a produtividade (a produção real per capita) introduzindo novas técnicas. Por outro lado, as regiões cuja produtividade aumenta ou poderia aumentar pela simples implantação das técnicas já conhecidas são consideradas em graus diversos de subdesenvolvimento. O crescimento de uma economia desenvolvida é portanto, principalmente, um problema de acumulação de novos conhecimentos científicos e de progressos na aplicação desses conhecimentos. $\mathrm{O}$ crescimento das economias subdesenvolvidas é, sobretudo, um processo de assimilação da técnica prevalecente na época. (FURTADO, 2009 , p. 85)

É curioso notar que, com o passar do tempo, posições antes vistas como opostas assemelham-se mais do que se poderia antes imaginar, quando confrontadas com desdobramentos posteriores. Neste contexto, tanto a modernização conservadora quanto o dependentismo compartilham o fato de que se inserem em um projeto de nação independente; durante o regime militar (19641985), enquanto se perseguia e torturava comunistas, reforçava-se a formação do sistema nacional de pós-graduação nas universidades públicas como parte de seu plano de aproximar o Brasil dos países do Primeiro Mundo. Há um notável contraste em relação à onda neoliberal, que encontra eco no período anterior aos impulsos desenvolvimentistas a partir da década de 1930. Enquanto colônia o Brasil era uma região legalmente subalterna; até a vinda da família real portuguesa em 1808, não lhe era permitido ter imprensa, indústrias ou universidades. Sua função como fornecedor de matérias primas e como mercado consumidor para produtos manufaturados na metrópole era estabelecido por lei hoje ele continua mantido por políticas públicas. Em sua conturbada história, desde 1930 até 2015, o desenvolvimentismo representou (tem representado?) o esforço de retirar o país desse papel histórico subordinado. ${ }^{10}$

Ora, historicamente, o projeto desenvolvimentista brasileiro sempre se deu de baixo para cima; mesmo no caso de intelectuais idealistas ou estadistas visionários, o caráter mais ou menos impositivo de um plano foi uma constante. Do choque da concepção abstrata (e como abstrata nunca desprovida de um elemento ideológico-afetivo) com a realidade das práticas sociais abre-se um espaço para o exercício da burrice. ${ }^{11}$ No caso da universidade, aquilo que deveria ser seu conceito regulador, a livre busca da expansão do conhecimento, esbarra em uma organização social que lhe é estranha. Universidades criadas ex nihilo, deparam-se não somente com a falta de profissionais adequados (afinal deveriam

\footnotetext{
${ }^{10}$ Neste contexto vale mencionar o excelente documentário de José Mariani, Um sonho intenso (2014) Disponível em: https://www.youtube.com/watch?v=2JwOKMup2rw

${ }^{11}$ Note-se que a USP, quando de sua fundação nos anos 30, resolveu o problema da incipiência de uma cultura acadêmica por meio da importação de professores estrangeiros.
} 
ter sido formados pelas universidades que agora inauguram), mas com todo um rol de vícios políticos arraigados, como o patrimonialismo e o coronelismo. Fundar um campus torna-se uma oportunidade para obter dividendos eleitorais. Seja como for, há três formas principais que a burrice pode assumir; em comum têm a ausência, como seu horizonte normativo de ação, uma imagem da universidade como um local produtor de saber, no qual este se move, por menos que seja. A primeira é a mentalidade escolar. Aqui o conhecimento tratado como inerte; ele é transmitido como algo estanque, idêntico a si mesmo, ou que pertence a um outro (três representações para dizer a mesma coisa), ao passo o conceito de universidade o projeta como dinâmico, como algo que contém falhas ou buracos, algo do qual o pesquisador se apropria. A beleza de uma imagem enfática de universidade vem da indissociabilidade entre o passar e o ir adiante, transferir e aprofundar, ensinar questionando e aprender pesquisando. Note-se que essa descrição não tem nada a ver com uma ideia de dificuldade, pois é plenamente possível lidar com os assuntos mais complexos e profundos de um modo escolar, sem intervir neles. Como ela não está envolvida em processos de descoberta, a escola de ensino superior possui uma relação muito direta com a ordem, que se influencia todas as práticas acadêmicas, desde as aulas e o processo de avaliação ${ }^{12}$, até a parte administrativa ${ }^{13}$. A representação da Capes como órgão opressor, quando na realidade é composta por membros da comunidade docente, vem dessa postura perante o saber.

Em estreita relação com a postura escolar há a burocrática. Também aqui há a ausência de uma visão do progresso do conhecimento, mas no lugar da ideia de missão, da qual muitas vezes estão imbuídos os educadores, a visada burocrática traz para a vida acadêmica as marcas da opressão do emprego, o aspecto simplesmente doloroso do mundo do trabalho. Aqui impera a separação entre o tempo do trabalho e o livre, uma distinção que via de regra não deveria fazer sentido para o mundo acadêmico (cf. ADORNO, 1977). ${ }^{14}$ Como o sujeito não está minimamente investido naquilo que faz, o seu horizonte é o da pura troca ("para que dar aulas na pós-graduação, se não ganho a mais por isso"?). Pior ainda, o professor burocrático não hesitará em se aproveitar da liberdade concedida à universidade de pesquisa (as horas voltadas para o estudo, a

\footnotetext{
${ }^{12}$ Toda e qualquer avaliação contém em si um germe de burrice, pois ela apaga de antemão a surpresa e o entusiasmo. Como tendência geral, quanto mais forte o pesquisador, menos sua libido estará voltada para as provas. Na graduação, lembro-me de uma professora que não dava dez para ninguém, porque a nota máxima era dela.

${ }^{13}$ Como os departamentos têm bastante autonomia de autogestão, não é raro que se imponham obrigações desnecessárias, como empecilhos para afastamento, a cobrança de permanência no campus, a submissão de planos de aula ao chefe de departamento ou coordenador da graduação etc. Muitas vezes a resistência à pesquisa se manifesta em frases como "nossa vocação é a graduação", ou "a responsabilidade maior da universidade é com o ensino", etc.

${ }^{14}$ A representação do cientista maluco na cultura de massa pode vir daí. Se ele gosta daquilo que faz, se trabalha com gosto, é porque deve ser louco. Com um giro no parafuso, no entanto, é possível perceber como o engajamento existencial com a profissão pode tornar-se um argumento para exploração: se você já faz o que gosta, por que precisa de um bom salário?
} 
flexibilidade da disposição do tempo, a falta de controle e cobrança na realização das atividades profissionais...), para trabalhar o menos possível. Trata-se de um double-bind, que mobiliza, seja o mundo do funcionalismo público, seja o da academia, conforme a situação, para evitar o esforço. E isso se aplica também às relações interpessoais. Justamente porque as regras são frouxas - e têm que ser, se o que importa é a liberdade do pensamento -, e o professor burocrático não consegue vislumbrar que sujeito e objeto possam misturar-se, surge a tendência de regular tudo. Daí a estranha convivência entre autonomia e sujeição, que tão bem se adequa àquele dito popular, "para os amigos, tudo; para os inimigos, a lei".

É sob a perspectiva do burocrata, igualmente, que se deve abordar as greves na universidade pública. Como qualquer outra paralização laboral, sua lógica subjacente é: "cessaremos nossas atividades por tempo indeterminado, até que nossas demandas sejam atendidas; até lá, a sociedade arcará com os danos causados pelo cancelamento do nosso trabalho". Isso, no entanto, não se ajusta à universidade, porque: 1 . as atividades urgentes, como os setores de emergência nos hospitais universitários, não param; 2 . os danos causados à sociedade não são perceptíveis imediatamente e só aparecem no longo prazo (e danos sem dúvida acontecem quando as greves tornam-se regulares, quase uma parte do calendário escolar); 3. esse raciocínio só funciona quando o sujeito não está implicado naquilo que faz, quando não é agente e paciente ao mesmo tempo. Se fosse para levá-lo às ultimas consequências, o professor teria não apenas que parar de dar aulas, mas também de pesquisar, fazer grupos de estudo, ler em casa ou mesmo pensar (em casa, no chuveiro...). Uma interrupção tão completa só se justificaria diante de uma grande urgência de mobilização política, o que a rotineirização das greves impede. $\mathrm{O}$ paroxismo do curto-circuito ocorre com o pensamento crítico (e.g. um curso sobre a indústria cultural), que ao ser suspenso depara-se com um grande vazio.

$\mathrm{O}$ professor burocrata ainda submete-se àquilo que entende por lei, que neste caso é fluída, uma vez que o ideal da universidade é a autogestão. Não é necessário muito para que ele se transforme no terceiro tipo, o do contraventor. Se no primeiro caso a universidade era vista como escola, e, no segundo, como repartição pública, agora ela é encarada como um espaço para se dar bem. Aqui, a falta de rigidez das regras não é utilizada para a sua manipulação, mas para seu rompimento. $\mathrm{O}$ rol das ilegalidades é grande; ele vai desde as menores infrações, como faltar às aulas, não comparecer às reuniões, ou dar bolsas para protegidos, passando pelas intermediárias, como não respeitar a dedicação exclusiva e trabalhar por fora, e chegando às mais graves, que geralmente envolvem a iniciativa privada. Estas últimas, por certo, são raras, e o grau de corrupção das universidades públicas é infinitamente inferior ao de muitos outros setores do serviço público. $\mathrm{O}$ importante a notar aqui é que essas três figuras produzem 
burrice, cada uma a seu modo e de acordo com as especificidades das disciplinas em que se inserem. ${ }^{15}$

\section{BURRICE LITERÁRIA}

A idiotice específica aos estudos literários deve ser derivada da estranha situação na qual se encontra seu objeto. A crise fundamental da literatura desde no mínimo a segunda metade do século XX é resultado de uma dialética da autonomia, um processo no qual, à medida que se abria o horizonte de possibilidade de representação, diminuía a capacidade das obras de se justificarem social ou mesmo ontologicamente. ${ }^{16}$ Quanto mais a literatura libertava-se de amarras externas, fossem elas de natureza religiosa, moral, jurídica, lógica etc., tanto mais questionável ficava sua função. O ideal grandes obras modernistas, como o Ulisses, de James Joyce, por exemplo, era o de um artefato o mais autogerado possível, que somente obedecesse às leis composicionais fornecidas por si mesmo, e que assim caçoasse das normas de praxe decoro que deveriam acompanhar qualquer narrativa. A absurda consistência interna era paga com a perda de relevância social. Isso não apenas colocava-se como horizonte de escrita das obras, obviamente elevando em muito o patamar daquilo que merecia ser chamado de literatura, como também fornecia novas bases para a crítica do passado. Os insights críticos de Roberto Schwarz (1991; 2000) a respeito de Machado de Assis, por exemplo, seriam estruturalmente impossíveis enquanto a questão do adultério fosse moralmente forte bastante para ofuscar o trabalho da forma em Dom Casmurro, ou enquanto os materiais díspares que compõem Brás Cubas não houvessem sido neutralizados em seu impacto no leitor. A autodeterminação formal possibilitou um salto da imaginação e da inteligência e não é à toa que praticamente tudo de interessante que aconteceu no pensamento do século $\mathrm{XX}$, com exceção da filosofia analítica, esteve de uma forma ou de outra relacionado com a literatura.

Esse desenvolvimento, contudo, ocorreu em paralelo com a consolidação da indústria da cultura, que, em que pese toda a diferenciação por que vem passando nas últimas décadas, possui fortes elementos geradores de homogeneidade. Dentre eles vale destacar aqui a noção de interioridade subjetiva, como riqueza individual. Surgem daí uma série de consequências, como a família como espaço ideal de formação do indivíduo ou a separação entre a esfera pública e privada como absoluta e organizando um firme sistema de valores, no qual está última é benévola e a primeira, malévola. Em suma, trata-se de um romantismo degradado. A consolidação, via repetição, de padrões representacionais acaba por

\footnotetext{
${ }^{15}$ Seria errado pensar que há inteligência no caso do burocrata e do corrupto; trata-se ao invés de esperteza, que está muito mais ligada à autopreservação; neste contexto, essas duas habilidades são díspares, quase contraditórias.

${ }^{16}$ Este é um dos pilares da Teoria Estética [Aesthetische Theorie ] (1973), de T.W. Adorno.
} 
estabelecer um horizonte próprio ${ }^{17}$, que por sua vez influencia o horizonte de expectativas da própria narratividade, daquilo que se imagina que possa ser uma história. Nada mais natural, portanto, que a imagem da literatura seja afetada pela indústria cultura, da qual é parte constitutiva. É por isso que, em qualquer universidade de qualidade, tanta ênfase é dada ao caráter científico e objetivo da interpretação e da crítica, tanto esforço é despendido em apagar a associação de literatura com aspectos pessoais - sempre correndo o risco, é claro, de purgar de tal modo o componente subjetivo da leitura, que no final são formados burocratas da exegese. Sob esse ângulo, a universidade deve funcionar como uma espécie de escudo, ou filtro ao menos, contra aqueles lugares comuns que se converteram em segunda natureza.

A presença praticamente absoluta da indústria da cultural tem como contraparte a ausência da representação social do trabalho do crítico, daquilo que se faz na universidade. Com efeito, existe um abismo entre aquilo que se imagina seria o trabalho do profissional da área e aquilo que de fato se faz. Grosso modo, tal imagem estaria ligada à prática escolar. Faz-se Letras para se tornar professor de português e de literatura. O primeiro caso não é o foco aqui, embora seja importante marcar que ainda é dominante a concepção tradicional, normativa de língua, como um âmbito regido pelo certo e pelo errado, o que a linguística já há muito vem questionando, e que a política linguística participa da geral de forma contundente $^{18}$. No que se refere à literatura, vale arriscar a tese de que a sua inserção social se dá a partir de uma associação com o mundo moral, em estreita conexão com a ideia de interioridade mencionada acima. Quando você diz para alguém que é professor de literatura, a pessoa muito frequentemente responde: "que bonito!". Esse "bonito" não é tanto um termo estético, não remete à contemplação de algo harmonioso, no qual parte e todo interagem simbioticamente; trata-se, mais do que isso, a algo que muito vagamente remete à esfera do Bem (além, é claro, de possuir conotações femininas - Letras e literatura como coisa de mulher). Neste contexto, a literatura seria um veículo ético, que faria as pessoas melhores, que demonstraria o Brasil (quando dizemos "nosso Machado de Assis"), em suma, algo que humanizaria. É interessante notar a posição constrangedora na qual se encontra o profissional de literatura, que escreve contra essa representação social quando está dentro da universidade, mas se vê por vezes incapaz de enfrentá-la em ambientes mais amplos, uma vez que a associação entre Literatura e o Bem é o maior pilar de sustentação social da área.

Há porém mais um elemento gerador de burrice, o último que gostaria de abordar aqui, embora obviamente existam outros. ${ }^{19}$ Trata-se da inserção da

\footnotetext{
${ }^{17}$ Adorno (1991) chega ao ponto de dizer que assim se produz um esquema em sentido kantiano, algo que pré-organiza a percepção.

${ }^{18}$ Por exemplo, seria interessante fazer um experimento no qual se reproduzisse a interação com a polícia de duas pessoas com os mesmos traços, porém com linguajares socialmente opostos.

${ }^{19}$ Por falta de espaço não abordaremos a pressão social que se impõe hoje à universidade, e que é tanto sintoma quanto causa de sua fraqueza presente. Apenas vale notar que aqui ocorre a conjunção de forças que se pensaria opostas, porque tanto as vozes defendem uma proximidade
} 
literatura na universidade produtivista, um desenvolvimento que vai em uma direção contrária aos outros, e que assim compõe um quadro intrigante. Se a instalação ex nihilo de universidades e a ausência de uma representação social adequada do profissional das Letras apontam para a falta de desenvolvimento, para o atraso, a academização da literatura traz problemas que são comuns aos países avançados, ainda que o Brasil lhes confira um toque periférico. A universidade acolhe a literatura com uma condição expressa: a de que forneça conhecimento, algo que a literatura sem dúvida é capaz de fazer, porém não sem um preço a pagar, como o enfraquecimento do prazer e do entusiasmo, enfim, daquilo que faria da literatura existencialmente significativa. Quando a exigência de gerar saber é crescentemente colocada como finalidade a priori no contato com o literário, abre-se a caixa de Pandora do cientificismo. A crescente disciplinarização e fragmentação dos campos de estudo ("studies" tornando-se uma espécie de sufixo delimitador); a quantificação, ou, melhor, a necessidade de mensurar e comparar; a fúria avaliadora; a burocratização da rotina acadêmicatudo isso deriva, ao menos em parte, do transplante de uma certa concepção de ciência para os estudos literários. O alemão possui uma palavra própria para isso, o Fachidiot. Trata-se de um processo que atinge a parte mais interna do convívio com a literatura, incluindo as estratégias de leitura, a escolha dos livros (agora chamados de corpus), o caráter dos argumentos etc. Para dar um exemplo, e para mostrar como a burrice é muitas vezes cômica, pense na inadequação da formaprojeto para os estudos literários e particularmente par ao processo interpretativo. Para ser honesto, na rubrica "metodologia" o pesquisador deveria escrever: "ler muitos textos, ter ideias, escrevê-las".

Mas a urgência do conhecimento, cuja base material é uma pressão sobre a universidade, que envolve a precarização dos postos de trabalho e a formação de um considerável exército intelectual de reserva ${ }^{20}$ leva também a um tipo bem contemporâneo de burrice, a teórica. Ela caracteriza-se por um grande investimento nos conceitos, como se realmente fossem confiáveis (o que os aproxima das mercadorias), o que incentiva uma lógica da moda, aqui entendida como um processo de substituição não regido pelo desdobramento imanente ao objeto, mas antes gerado pelo poder dos veículos de circulação. Artigos e mais artigos são escritos com o objetivo de mobilizar certos termos em voga (e como mencionado anteriormente, tentar conseguir um emprego); teorias são aplicadas aos mais diversos (e díspares) objetos. Uma forte distinção impõe-se: a literatura não sabe nada de si; ela é toda ignorância e passividade, ao passo que a teoria, instrumento por excelência, não possui espessura, e é toda luz. ${ }^{21}$ No que se refere

maior ao mercado, quanto as que reivindicam uma maior representatividade de grupos específicos representam demandas à universidade. Para as implicações disso para o debate sobre o cânone literário, cf. Durão (2013).

${ }^{20}$ Vale pensar sobre os possíveis efeitos sociais desse contingente de cérebros desempregados, como observa Robert Hullot-Kentor (DURÃO, 2012, p. 36-39).

${ }^{21}$ Para uma discussão da theory como uma nova formação discursiva, tipicamente norteamericana, cf. Durão (2011), entre outros. 
ao Brasil, é importante enfatizar o desequilíbrio das trocas intelectuais. A teoria raramente é forjada nacionalmente e os pesquisadores brasileiros, que trabalham bastante, leem mais europeus e norte-americanos do que discutem entre si. A menoridade intelectual é reproduzida com afinco e bastante esforço.

Obviamente, haveria muito mais que dizer. Como enfatizado no começo, para cada instância acadêmica existe uma manifestação emburrecedora que lhe é correspondente, e seria possível demorar-se determinadamente em outros tipos de idiotice, como por exemplo a filológica, a departamental, a didática etc. etc. Este texto, portanto, é mais bem lido como um convite à reflexão e à extrapolação do que como descrição exaustiva. Ele é suficiente, porém, para deixar entrever uma conclusão irônica, a saber, que por mais multifacetada e ubíqua, por mais abrangente e obstinada, a burrice acadêmica nunca é forte bastante: dentre as forças que no momento globalmente se empenham para destruir a universidade, a estultice não é a preponderante.

\section{REFERÊNCIAS}

ADORNO, T.W. Aesthetische Theorie. Gesammelte Schriften. Bd. 7. Frankfurt a.M.: Suhrkamp, 1973.

1977.

Freizeit. IN: Gesammelte Schriften, Bd. 10.2. Frankfurt a.M.: Suhrkamp,

The Schema of Mass Culture. IN: J.M. Bernstein (Ed.) The Culture Industry. Selected essays on mass culture. Londres e Nova Iorque: Routledge, 1991.

ADORNO, T.W. HORKHEIMER, Max. Dialektik der Aufklärung. Frankfurt a.M.: Fischer Verlag, 1988 [1947]

ALTHUSSER, Louis. Sur la reproduction. Paris: Presses Universitaires de France, 1995.

COLLINI, Stefan. Speaking of Universities. Londres e Nova Iorque: Verso, 2017.

DERRIDA, Jacques. A Universidade sem Condição. Traduzido por Evando Nascimento. São Paulo: Estação Liberdade, 2003.

2008.

. Séminaire La bête et le souverain: Tome 1, 2001-2002. Paris: Galilée,

DURÃO, Fabio Akcelrud. Teoria (literária) americana: uma introdução crítica. Campinas: Autores Associados, 2011. 